\title{
Fod Practice
}

BDA Good Practice is a framework for continuous improvement that helps you build seamless systems and develop a confident and professional dental team, and there's nothing that builds team ethos like uniting behind a campaign.

From the BDA's cut sugar campaign to the BDHF's National Smile Month and Mouth Cancer Action Month, here are four Good Practice members who have gone the extra mile to raise awareness of some key campaigns in the dental profession.

\section{Part 1: Charles Landau Dentistry}

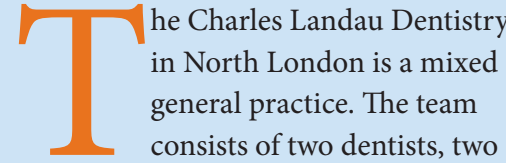

nurses, a receptionist and a practice manager. Staff have been treating patients for over 40 years, whilst seeing changes in the local community within a varied social and economic mix - typical of the inner London area of Islington. The practice have been members of BDA Good Practice for 10 years. As part of membership, the practice promotes oral health to patients and participates in local public health and dental health initiatives.

Karen Suarez, practice manager, shared with us how the practice team have been engaging with their patients to get them thinking about sugar and oral health as part of our ongoing campaign to cut sugar consumption.

\section{What have you done within} practice to raise awareness of sugar consumption?

We are proactive within the community regarding oral health. We partake in National Smile Month and Mouth Cancer Action Month as well as having an ongoing oral health programme. We have good relationships with our local reps from dental companies and they often supply us with samples to go in goodie bags for our demonstrations. We have always discussed sugar with our patients, especially hidden sugars. We have created an educational poster as part of our visual display, demonstrating the different sugars

called 'sugar by any other name' and explained that anything ending in 'ose' on an ingredient label would be sugar.

Nowadays instead of talking about the consequences of Ribena in babies' bottles we are speaking about the consequences of frequently drinking smoothies and the perils of dried fruit.

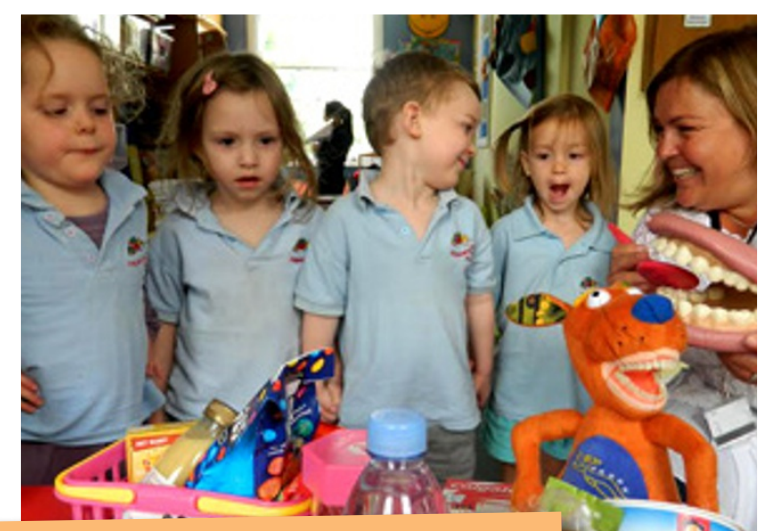

\section{WITH OUR AGEING POPULATION IT WAS}

\section{IMPORTANT NOT TO FORGET THE ELDERLY}

How have you engaged children in the subject?

We have had some fun open days promoting oral health. We made a tooth fairy grotto, where one of our dentists dressed up as a tooth fairy and the rest of the team dressed up as a good fairy, a bad fairy and a caring fairy. The good fairy had inter-dental brushes, floss, toothbrushes and toothpaste pinned on her tutu and the bad fairy had lollipops, sweets and fizzy drinks pinned on hers.

We have also visited local rehabilitation centres and older sheltered accommodation homes. We felt it was vital to target not only children but to focus on other vulnerable groups. With our ageing population it was important not to forget the elderly, with whom we discussed denture care, root sensitivity and oral cancer.

What benefits have you seen from your activities?

We engaged children and families who may have never visited otherwise. The children and parents loved all the activities we have conducted and we received incredible responses from all involved. It was good for our practice profile within the community and local organisations including the CQC. We were inspired to begin all our activities when we first applied for BDA Good Practice, as one of the requirements to gain membership is to engage with the local community. As a result it has been beneficial for us as a team, the practice and our patients. 


\section{Part 2: Osborne Dental Group}

P

rincipal dentist at the Osborne Dental Group, Dr Onkar Dhanoya, shared with us how the practice team have been engaging with their patients to get them thinking about sugar and oral health as part of the ongoing campaign to cut sugar consumption across their three practices in the North East.

What have you done within practice to raise awareness of sugar consumption?

Stanley Dental has introduced special clinics offering prevention, diet and oral hygiene advice to patients every three months, to motivate them to maintain good dental health habits between checkups. As part of this, patients are given a questionnaire to fill out, so that their dentists can learn about what they are eating and drinking, and can advise them how to cut down on their sugar intake.

Stanley Dental is also very active within the community and has visited local primary schools to host workshops for children, explaining the effect that sugar has on teeth. Additionally, children have paid visits to the practice on school trips to meet the dentists and learn about what treatments they carry out in their surgeries.

The Osborne Dental Group has also filmed an in-house video offering advice about how to keep your teeth healthy and which foods to avoid. The video is one of several clips on the group's YouTube channel, which patients can refer to for advice about a range of topics - from mouthwash to wisdom teeth.

The group spreads the word about the risks of high sugar intake on social media, and backs the work of Dr Aseem Malhotra - cardiologist and adviser to the campaign group Action on Sugar. Currently, Dr Onkar Dhanoya, as regional chair of the LDC, is using Twitter to campaign for the documentary @thatsugarfilm, to encourage North East venues to show the sugar film which has been shown in Parliament and is to be screened in the North East.

Dr Onkar Dhanoya is also on the board of the Faculty of General Dental Practice, which is among the organisations calling on the Government to explore the scope for using sales taxation and advertising

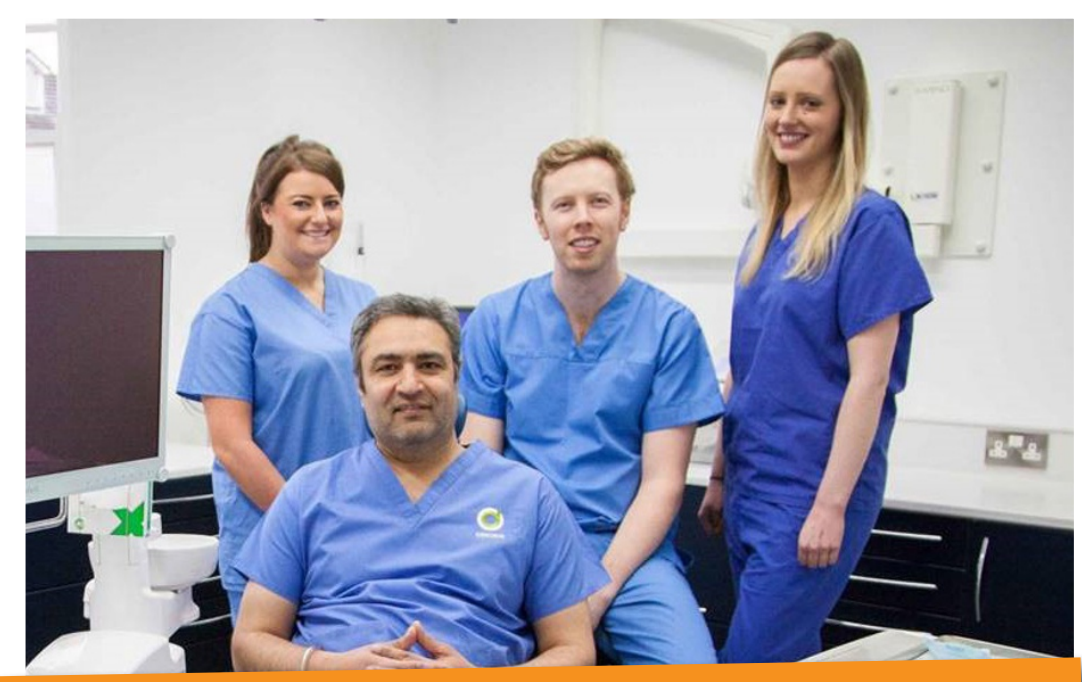

'THEY ASSUME THEY ARE MAKING A HEALTHY

\section{CHOICE BUT FAIL TO RECOGNISE THAT}

THERE IS OFTEN STILL A HIGH AMOUNT OF

\section{SUGAR IN THESE PRODUCIS.}

restrictions to counter the damage done by high levels of sugar consumption.

Lastly, Osborne Dental promotes National Smile Month in the community every year.

\section{How have your patients} responded to what the practice is doing to raise awareness?

The clinics at Stanley Dental are wellattended and patients particularly appreciate the one-on-one time with their dentist to analyse their diet, so that they can pinpoint where exactly they are consuming too much sugar. What has repeatedly come to light is that the term 'no added sugar' in fruit squashes and other products is very misleading for patients. They assume they are making a healthy choice but fail to recognise that there is often still a high amount of sugar in these products.

Feedback from the school visits has been extremely positive. Parents have commented that their children have come home from school asking for new toothbrushes and have been taking much more of an interest in their teeth-cleaning routines.
What benefits have you seen from your activities?

Patients have been very receptive to the information. When they are educated personally about the dangers of sugar intake and see how it affects their teeth and their overall health - on an individual level, they are then encouraged to make changes to their diet. By keeping track of their progress every three months in the clinics at Stanley Dental, patients are then able to see improvements first-hand, which in turn gives them the motivation to keep going with their improved dental care routines.

Similarly - when parents see their children taking an interest in dental care following Stanley Dental's visits, it has in turn encouraged them to schedule check-ups on a regular basis and to keep the whole family engaged in good dental hygiene habits. 


\section{FEATURE}

\section{Part 3: The Dental Care Centre}

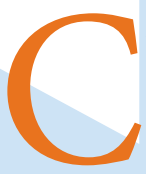

lare Nichols, Practice Manager at The Dental Care Centre in Folkestone, shared with us how the practice team have been engaging with their patients to get them thinking about sugar and oral health.

\section{What have you done within practice to raise awareness of sugar?}

As a practice we passionately believe in improving and maintaining oral health. Over the years we have increased the amount of information given to patients so they are able to make more informed choices about lifestyle, diet and active home prevention. Getting the message across to our patients through multiple mediums is our practice goal. Social media is growing in popularity and so we are thinking more about how we can use Twitter to engage our patients.

The team carries out a range of activities to target and interact with our patient base. We have Dental Nurses who have attained an additional qualification in Oral Health Education. The Oral Health Advisors have the ability to spend time with our patients to discuss the implications of sugar on their teeth and general health. This is a great asset to parents who need additional support in educating their children.

We have created various displays in our waiting rooms to raise awareness of sugar and one of the Oral Hygiene Nurses has made a great food game which is very hands on and interactive for young children.

The team also visits schools and nurseries to educate young children on the 'naughty sticky bacteria' caused by sugars. This gives us the opportunity to wear fun costumes that the kids absolutely love and engage with. We give away free goody bags with a toothbrush, stickers, brushing charts, bottled water and advice for parents to reinforce our message.

\section{How have your patients} responded to what the practice is doing to raise awareness?

The schools and nurseries have given us great feedback and it puts smiles on our faces when the children's 'thank you' drawings and cards arrive on our doorstep.

It's amazing that many patients may think certain foods or drinks are healthy, such as fruit smoothies, when really they can be full of hidden sugars that are being consumed several times throughout the day.

Over the years, our sugary drinks displays have been the most successful way to get the message across. Not only for children but adults who just do not realise how much hidden sugar can be in some drinks.

Our dentists' advice, along with all the other ways the team reinforces our messages, has resulted in an improvement in some patients' oral health - down to the change in their diets and adopting a good oral hygiene routine.

\section{How receptive have the patients been to the information?}

Patients have warmly welcomed what we are trying to do. The younger patients love the games and interactive displays that we have. Some of the teenagers have made life-changing alterations in the way they

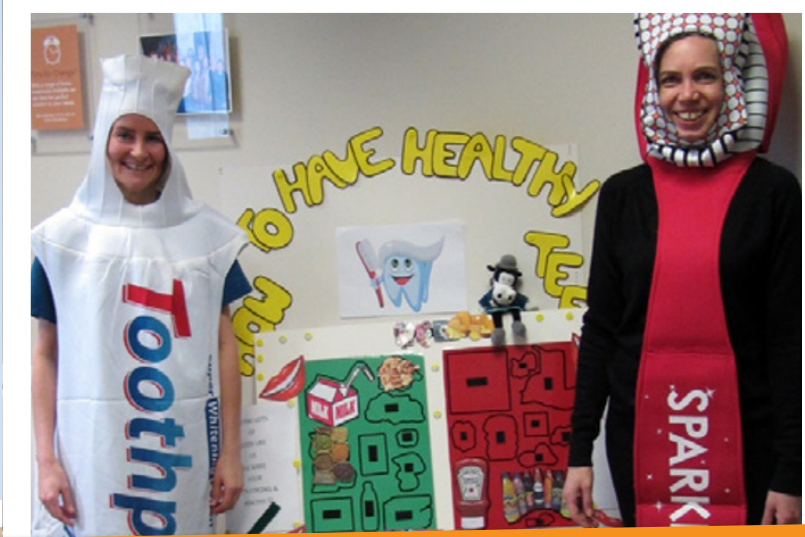

care for themselves at home and this is a direct result of being willing to take on-board the messages from our Oral Hygiene Nurses. Teenagers don't always tend to listen to their parent's advice. A lot of grandparents now carry out

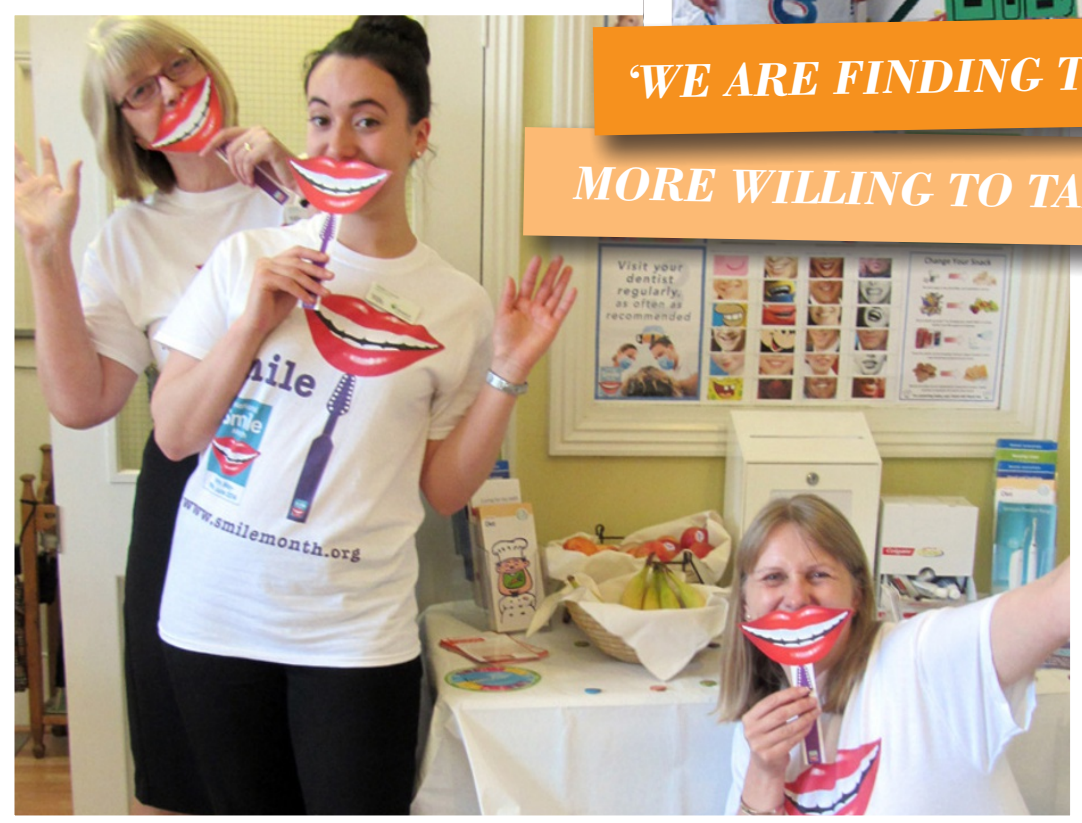

WWE ARE FINDING THAT SOMIE PATIENTS CAN BE 


\section{Part 4: Hob Hey Dental Care}

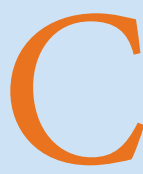

linical Director, Dr John Fleming has been involved with the Culcheth-based practice for over 17 years, and shared what his practice has been up to.

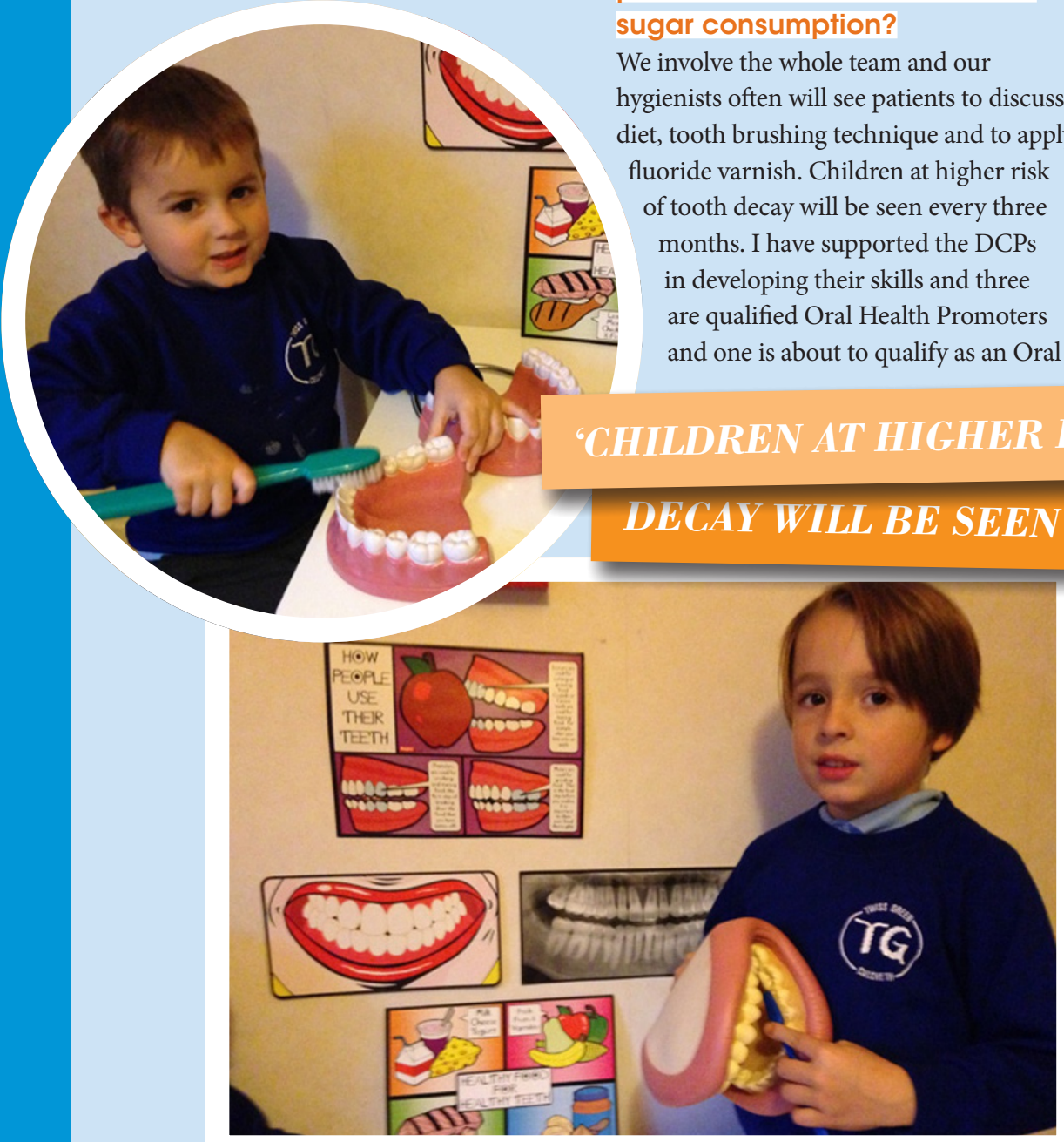

How have your patients

responded to what the practice is doing to raise awareness?

We have always been of the opinion that prevention is better than a cure, so an integral part of each examination is discussing diet and advising patients and parents of our younger patients of the dangers of frequent snacking on sugary foods and drinks and of the dangers of hidden sugars. It is amazing how many parents are shocked to learn that fruit juice is bad for teeth as they have been led to believe it is an effective way of getting one of their 5-a-day, unaware of the terrible damage it can have on teeth, especially children's teeth. We have found that informing parents and grandparents of this has led to an improvement in the diets of the children and this has also had beneficial effects on the oral health of our patients of all generations.

\section{What have you done within} practice to raise awareness of sugar consumption?

We involve the whole team and our hygienists often will see patients to discuss iet, tooth brushing technique and to apply uoride varnish. Children at higher risk

f tooth decay will be seen every three months. I have supported the DCPs in developing their skills and three are qualified Oral Health Promoters and one is about to qualify as an Oral mums, dads and grandparents to the session, so we can hopefully help the whole family.
Every year we go to the local school to talk to the 6-7 year olds in conjunction with their 'healthy eating' week. These sessions are really good fun and the children enjoy looking at the equipment we use and we play games such as guessing which foods have hidden sugars and we all have a turn at brushing teeth correctly on our giant tooth model. They really enjoy their goody bags that we provide which are filled with toothbrushes, toothpastes, hidden sugar charts, stickers and rewards charts and we have had feedback from parents saying that these sessions have really changed their children's eating habits and it has had a positive effect on the whole family.

I am a Beaver Leader in our local Beaver group and we have a dentist week where we do experiments on coins in Coca-Cola, Diet Coke and milk. They love drilling the play dough teeth!

What benefits have you seen from your activities?

In our experience getting the children involved in a fun and engaging way, whether it is at the practice, at school or in local clubs, is the best way to educate them from a young age It also has a beneficial effect on the whole family.

We use Facebook and Twitter to inform patients of the dangers of sugar and our website has an Oral Health for Children page with videos demonstrating tooth brush techniques appropriate to the age of the child. There is a Kids Kingdom page where children can play interactive games and read stories and facts about teeth. One of our dentists has made a video demonstrating how many cubes of sugar are in common every day drinks and we have uploaded this to our website, Facebook and Twitter pages.

There are so many different ways to get the message across and hopefully we will see some positive changes over the next few years so we can help to reduce the damaging effects of a completely preventable disease. 